\title{
Evolução do Segmento Norte do O rógeno Itabuna-Salvador-Curaçá: Cronologia da Acresção de Arcos, Colisão Continental e Escape de Terrenos
}

\author{
Elson Paiva O liveira ${ }^{1}$ (elson@ ige.unicamp.br), Marcelo Juliano de Carvalho ${ }^{1}$, Neal J. McNaughton ${ }^{2}$ \\ ${ }^{1}$ Departamento de G eologia e Recursos Naturais - Instituto de Geociências - UNICAMP \\ Caixa Postal 6.152, CEP 13083-970, Campinas, SP, BRA \\ ${ }^{2}$ School of Earth and Geographical Sciences - University of Western Australia, Crawley, AUS
}

Palavras-chave: geotectônica, faixas orogênicas, geocronologia, isótopos de $\mathrm{Nd}$.

\section{RESUMO}

Datações de alta precisão em zircões (U-Pb e $\mathrm{Pb}-\mathrm{Pb}$ ) e dados $\mathrm{Sm}-\mathrm{Nd}$ e $\mathrm{Pb}-\mathrm{Pb}$ em rocha-total são utilizados para reconstituir a evolução tectônica do Segmento Norte do Orógeno Itabuna-Salvador-Curaçá, nordeste do Cráton São Francisco. Acresções de crosta oceânica e/ou arcos insulares ocorreram há cerca de 3,3 Ga (Greenstone Belt Mundo Novo) e entre 2,2 2,12 Ga (Greenstone Belt do Rio Itapicuru e Seqüência Rio Capim). Margens continentais ativas, tipo andina, podem ter-se formado entre 3,08 - 2,98 Ga (migmatitos e TTG de Retirolândia-Santa Luz e granulitos do vale do Rio Jacurici) e 2,69 - 2,63 Ga (Complexo Caraíba). Entretanto, a colisão continental que construiu a estruturação atual do orógeno deve ter acontecido por volta de 2109 Ma, como inferido da intrusão sintectônica do Tonalito Itareru, no limite entre o Greenstone Belt do Rio Itapicuru e gnaisses bandados do embasamento, no Bloco Serrinha. A continuação da colisão provocou escapes laterais de blocos (Bloco Uauá) e intrusão de corpos graníticos alongados (Sienito Itiúba, domo de Ambrósio, quartzo-monzonito Capela do Alto Alegre) ao longo do orógeno, entre aproximadamente 2084 Ma e 2039 Ma. A mudança de tectônica de convergência de massas continentais para deslocamento de blocos ao longo do orógeno pode ter resultado de colisão oblíqua ou de tectônica de endentação.

Keywords: geotectonics, orogenic belts, geochronology, Nd isotopes.

\begin{abstract}
$\mathrm{U}-\mathrm{Pb}$ and $\mathrm{Pb}$-evaporation zircon ages, together with whole-rock $\mathrm{Sm}-\mathrm{Nd}$ and $\mathrm{Pb}-\mathrm{Pb}$ data, are used to unravel the tectonic evolution of the northern segment of the Itabuna-Salvador-Curaçá Orogen, northeastern São Francisco Craton. The results of this geochronologic study indicate that oceanic crust and island arc sequences accreted at $3.3 \mathrm{Ga}$, forming the Mundo Novo Greenstone Belt, and that between 2.2 - 2.12 Ga the Rio Itapicuru and Rio Capim Greenstone Belts were formed in a similar fashion. Age data and $\mathrm{Nd}$ isotopes also suggest that Andean-type continental margins are likely to have formed in the span of time 3.08 - $2.98 \mathrm{Ga}$, giving rise to the TTG belts of Retirolândia and Jacurici river, and to the Caraíba Complex between 2.69 - $2.63 \mathrm{Ga}$. Around $2109 \mathrm{Ma}$, continent-continent collision closed the Rio Itapicuru volcano-sedimentary basin, as inferred from the syntectonic emplacement of the Itareru Tonalite between the Rio Itapicuru Greenstone Belt to the east and the banded gneisses of the Serrinha Block to the west. This collision culminated in a major shift from frontal or oblique convergence to orogen-parallel block-escape about $2084 \mathrm{Ma}$ ago and continued at least till $2039 \mathrm{Ma}$. During this event several elongated granitic and syenitic bodies were emplaced in the continental crust. The Itiúba Syenite, dated at 2084 Ma and stretching over $150 \mathrm{~km}$ east of the Caraíba Complex, is an example of one of these intrusive bodies.
\end{abstract}




\section{IN TRO DUÇÃO}

O Orógeno Itabuna-Salvador-Curaçá compreende uma faixa contínua de rochas de alto grau metamórfico que se estende desde o sul até o norte do estado da Bahia, por mais de 800 km (Figura 1). Na latitude de Salvador, aparentemente ele se desmembra em dois ramos, um segue para nordeste ao longo da linha de costa e o outro para norte pelo interior. Na porção meridional, ele situa-se entre o núcleo arqueano de Jequié e o Oceano Atlântico, enquanto na setentrional, o ramo interior está confinado entre os blocos arqueanos de Gavião-Mairi, a oeste, e Uauá-Serrinha, a leste. Na sua porção sul, é conhecido por Cinturão Granulítico da Costa Atlântica (Mascarenhas, 1979), Cinturão Móvel da Costa Atlântica (Costa \& Mascarenhas, 1982) ou Cinturão Granulítico de Itabuna (Figueiredo, 1989; Barbosa, 1990) e, na porção norte, por diversos nomes como Cinturão Salva-
dor-Curaçá (Santos \& Souza, 1985; Barbosa, 1997), Orógeno Curaçá-Ipirá (Padilha et al., 1990), Cinturão Móvel Salvador-Curaçá (Padilha \& Melo, 1991; Melo, 1995) ou Orógeno Salvador-Curaçá (Oliveira et al., 1999).

Para fins descritivos, o Cinturão Salvador-Curaçá e o Cinturão Granulítico de Itabuna são respectivamente designados como Segmento Norte e Segmento Sul do Orógeno Itabuna-Salvador-Curaçá, de acordo com o estabelecido em Barbosa et al. (2001).

O orógeno tem sido objeto de diversos estudos geológicos motivados principalmente pelo seu elevado potencial metalogenético (Cu em Caraíba, Cr em Medrado, Santa Luz e Campo Formoso, Au em Jacobina e Fazenda Brasileiro) e de correlação geotectônica.

Neste artigo são apresentadas e discutidas informações geológicas e geocronológicas recentes sobre o Segmento Norte do Orógeno Itabuna-Salvador-Curaçá.

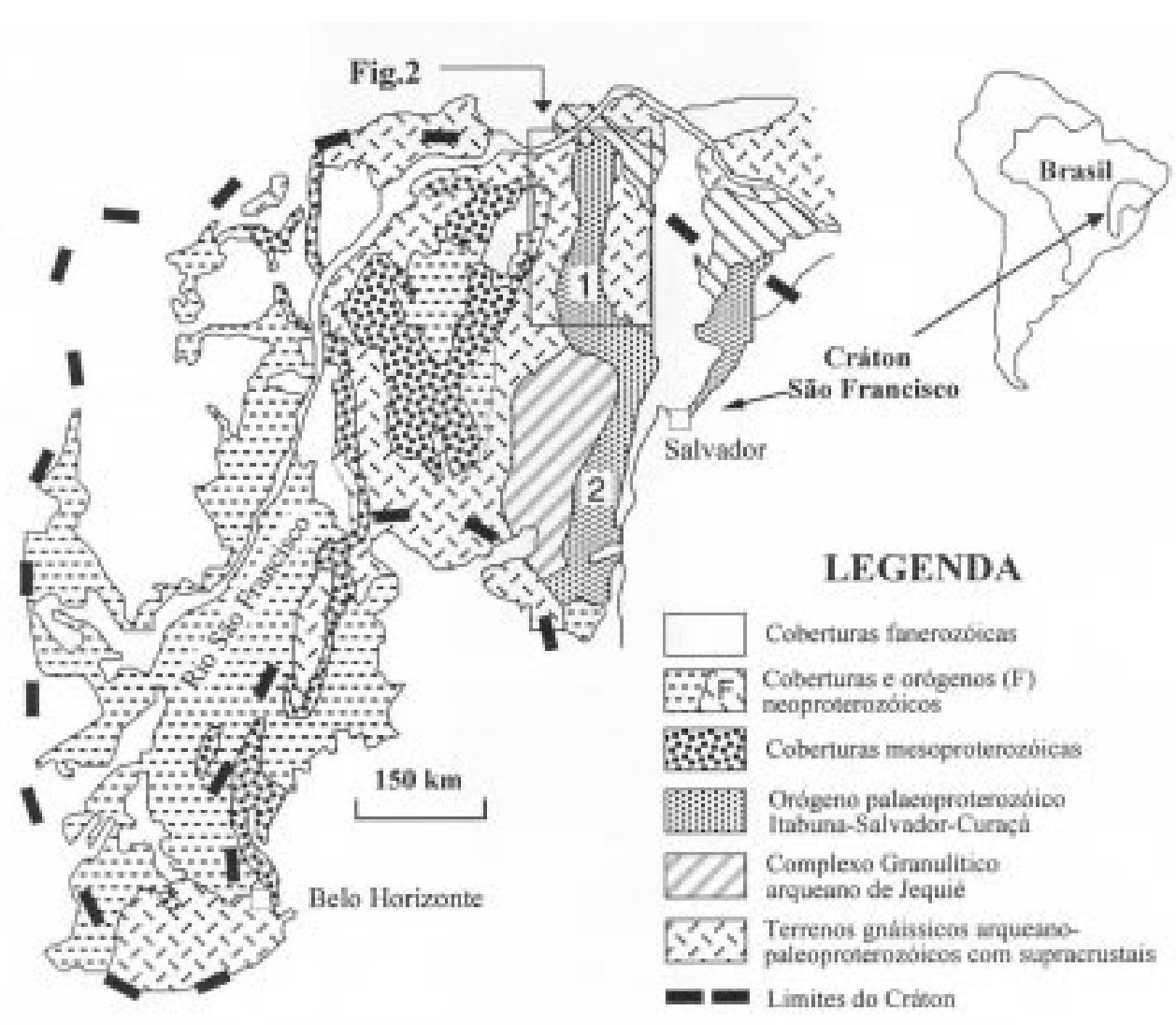

Figura 1. Localização do O rógeno Itabuna-Salvador-Curaçá no Cráton São Francisco e identificação dos Segmentos Norte (1) e Sul (2). Modificado de O liveira \& Tarney (1995). 


\section{EVOLUCCÃO GEOTECTÔNICA DO ORÓGENO ITABUNA-SALVADOR-CURAÇÁ}

Os modelos geotectônicos para o Orógeno Itabuna-Salvador-Curaçá, durante o Paleoproterozóico, sugerem um estágio final de colisão continente-continente similar aos descritos no Fanerozóico (Barbosa, 1990, 1997; Figueiredo, 1989; Padilha \& Melo, 1991; Teixeira \& Figueiredo, 1991; Figueiredo \& Barbosa, 1993; Silva, 1997; Ledru et al., 1994, Teixeira et al., 2000; Silva et al., 2001; Barbosa \& Sabaté, 2002; Oliveira et al., 2002a).

Segundo Barbosa (1990), Figueiredo \& Barbosa (1993), Ledru et al. (1994), Barbosa (1997) e Barbosa \& Sabaté (2002) o Segmento Sul do Orógeno Itabuna-Salvador-Curaçá seria a expressão final da colisão entre o maciço do Gabão (ou África Ocidental) e o microcontinente Jequié, evoluindo segundo a seguinte seqüência de eventos:

1. $(2,6 \mathrm{Ga}$ - 2,4 Ga) - edificação de um arco magmático de margem continental, subdivido em três domínios:

- domínio sudeste - rochas vulcânicas e plutônicas em facies granulito de composição química similar àquelas de arcos magmáticos modernos. Incluem suítes shoshoníticas, cálcio-alcalinas e tholeiíticas, bem como metabasaltos ricos em Fe e Ti e metassedimentos manganesíferos;

- domínio noroeste - enderbitos a charnockitos (cortados por gabro-anortosito) e rochas metavulcânicas e metassedimentares em facies granulito, às vezes migmatizadas. Os granulitos máficos têm assinatura geoquímica semelhante a basaltos de fundo oceânico ou de retro-arco.

- domínio central - intercala-se aos outros dois, consistindo de gnaisses bandados compostos por bandas de anfibolitos e gnaisses félsicos em facies anfibolito. Quimicamente, essas rochas assemelhamse às suas equivalentes em facies granulito, mencionadas nos outros domínios.

2. (2,4 Ga - 2,2 Ga) - intrusão de rochas monzoníticas/ monzodioríticas de filiação shoshonítica/alcalina;

3. $(2,07 \mathrm{Ga}-2,08 \mathrm{Ga})$ - colisão continente-continente e metamorfismo em facies granulito.

Para o Segmento Norte do orógeno, os dados geocronológicos e geológicos apontam para o envolvimento de um longo ciclo de retrabalhamento do embasamento (Sabaté et al., 1994; Silva et al., 1997; Oliveira et al., 2000), acresção de seqüências supracrustais e complexos plutônicos aos blocos arqueanos e colisão continental (Teixeira \& Figueiredo, 1991; Melo, 1995; Ledru et al., 1997;
Silva, 1997; Oliveira et al., 2002a).

A seguir serão apresentadas as unidades que compõem este segmento do orógeno e em seguida serão discutidos os dados geocronológicos.

\section{UNIDADES DO SEGMENTO NORTE DO ORÓGENO ITABUNA-SALVADOR-CURAÇÁ}

Uma revisão sobre as unidades geológicas que compõem o Segmento Norte do orógeno e núcleos cratônicos adjacentes pode ser encontrada em Kosin et al. (1999), Souza et al. (2000) e Kosin et al. (2001). Uma síntese é apresentada a seguir.

Esta região do orógeno (Figura 2) consiste de um núcleo central dominado por rochas granodioríticas a tonalíticas de alto grau metamórfico (Complexo Caraíba), intrusivas ou em contato tectônico com gnaisses aluminosos, anfibolitos, gnaisses grafitosos, formações ferríferas, mármores e rochas calcio-silicáticas das unidades Tanque Novo, no vale do Rio Curaçá, a norte, e Complexo Ipirá, a sul. Essas unidades e rochas máfico-ultramáficas da Suíte São José do Jacuípe, a sul, foram posteriormente cortadas por corpos alongados na direção N-S, de composição granítica a sienítica, cujo principal representante é o Sienito Itiúba.

Migmatitos, gnaisses bandados, ortognaisses diversos, diques máficos e complexos máfico-ultramáficos do Bloco Serrinha ocorrem à leste deste núcleo central (Figura 2). Essas rochas estão sobrepostas por, ou em contato tectônico com as seqüências supracrustais do Greenstone Belt do Rio Itapicuru, Rio Capim e Faixa Caldeirão, que por sua vez são cortadas por granitóides diversos.

O núcleo central do Segmento Norte do orógeno é bordejado, a oeste, por rochas supracrustais do Complexo Saúde (paragnaisses, xistos, quartzitos, metaconglomerados, rochas calcio-silicáticas, formações ferríferas, gonditos) e gnaisses e migmatitos arqueanos do Complexo Mairi. Gradativamente para oeste, ocorrem as seqüências supracrustais do Complexo Itapicuru ou Greenstone Belt Mundo Novo (quartzitos, metacherts, filitos, meta-siltitos, xistos, formações ferríferas, metaconglomerados, vulcânicas félsicas a máficas), Grupo Jacobina (metaconglomerados, quartzitos, ortoquartzitos, xistos grafitosos e rochas máficoultramáficas) e migmatitos e gnaisses arqueanos do Bloco Gavião/Complexo Mairi.

Vários corpos máfico-ultramáficos ocorrem no Segmento Norte do orógeno, boa parte deles contêm depósitos minerais. Este é o caso do Complexo Norito-hiperstenítico de Caraíba, hospedeiro de sulfetos de cobre, e dos Complexos Peridotíticos de Medrado, Campo Formoso e Santa Luz, mineralizados em cromita. 


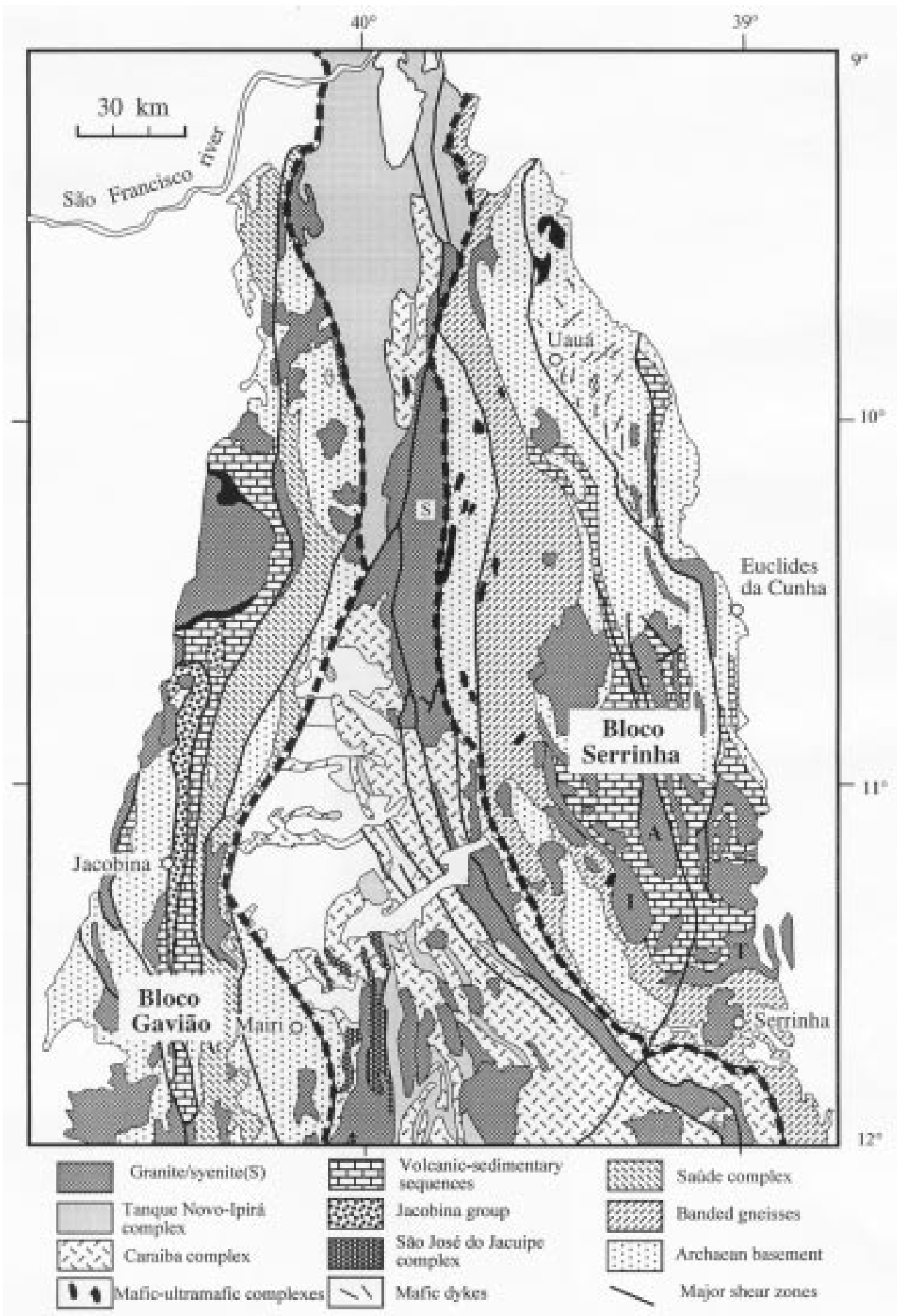

Figura 2. Mapa geológico do Segmento N orte do O rógeno Itabuna-Salvador-Curaçá, modificado de Kosin et al. (2003). Intrusões no Greenstone Belt do Rio Itapicuru: A - Ambrósio; I - Itareru; T - Teofilândia. Linhas tracejadas definem os limites aproximados dos Blocos G avião e Serrinha. 


\section{DADOS GEOCRONOLÓGICOS}

Neste item, são considerados preferencialmente os dados geocronológicos de alta precisão (U-Pb SHRIMP e diluição isotópica em zircões), disponíveis na literatura ou inéditos, e subordinadamente aqueles de evaporação de $\mathrm{Pb}$ em zircões. Para algumas unidades, por exemplo vulcânicas máficas e félsicas do Greenstone Belt do Rio Itapicuru, não há dados dessa natureza e conseqüentemente as isócronas $\mathrm{Pb}-\mathrm{Pb}$ em rocha-total foram consideradas. Sempre que possível idades em zircões são combinadas com os dados Sm$\mathrm{Nd}$ em rocha-total para fins de interpretação geotectônica.

\section{Bloco Gavião - Complexo Mairi}

Este bloco e o de Serrinha-Uauá contêm as rochas gnáissicas e migmatíticas mais antigas da região (e. g. Martin et al., 1991; Nutman \& Cordani, 1993; Martin et al., 1997; Paixão \& Oliveira, 1998; Oliveira et al., 1999; Cordani et al., 1999; Oliveira et al., 2002a; Rios, 2002; Oliveira et al., 2003) e são considerados como representantes dos microcontinentes que colidiram no Paleoproterozóico, para formar o Orógeno Itabuna-Salvador-Curaçá.

Na porção nordeste do Bloco Gavião, de interesse para o Segmento Norte do orógeno Itabuna-Salvador-Curaçá, Mougeot et al. (1996) relatam idades U-Pb em zircões de migmatito no intervalo 3450 - $3402 \mathrm{Ma}$, enquanto Peucat et al., (2002) determinaram idades mínimas de 3025 Ma e 3040 Ma por evaporação de $\mathrm{Pb}$ em zircões de gnaisses do Complexo Mairi. Para este complexo, as idades modelo $\mathrm{Nd} \mathrm{em}$ relação ao manto empobrecido $\left(\mathrm{T}_{\mathrm{DM}}\right)$ variam no intervalo $3,20-3,46 \mathrm{Ga}, \operatorname{com} \boldsymbol{\varepsilon}_{\mathrm{Nd}(3040 \mathrm{Ma})}$ entre -0,71 e -4,21 (Tabela 1).

\section{Greenstone Belt Mundo Novo (Complexo Itapicuru)}

Essa seqüência vulcano-sedimentar foi descrita em detalhe por Mascarenhas \& Silva (1994), porém dados geocronológicos de alta precisão só foram divulgados recentemente. Peucat et al., (2002) apresentam idade U-Pb SHRIMP de $3305 \pm 9$ Ma em metadacito do greenstone belt, revelando ser uma das seqüências supracrustais mais antigas desta porção do Craton São Francisco. As idades modelo $\mathrm{T}_{\mathrm{DM}}$ para os metadacitos situam-se no intervalo 3,58 $3,37 \mathrm{Ga}, \operatorname{com} \boldsymbol{\varepsilon}_{\mathrm{Nd}(3305 \mathrm{Ma})}$ entre $0,49 \mathrm{e}-1,94$ (Tabela 1$)$.

\section{Bloco Serrinha-Uauá}

Na região de Uauá, Paixão \& Oliveira (1998) apresentam isócrona $\mathrm{Pb}-\mathrm{Pb}$ de $3161 \mathrm{Ma}$ para anortositos do Complexo Lagoa da Vaca e idade de 3072 Ma por evaporação de $\mathrm{Pb}$ em zircões de granulito, enquanto Cordani et al. (1999) determi- naram idades U-Pb SHRIMP entre 3,12 e 3,13 Ga para o Tonalito Capim. Idades para outros ortognaisses do Bloco Uauá (2933 \pm 3 Ma e $2991 \pm 22$ Ma, U-Pb diluição isotópica de zircões) e da Faixa Caldeirão ( $3152 \pm 5 \mathrm{Ma}$, U-Pb SHRIMP em zircões) são apresentadas em Oliveira et al. (2002a) e Mello et al. (1999a).

Mais para sul, Oliveira et al. (2002b; Oliveira et al., 2003) apresentam idades U-Pb SHRIMP (zircões) de $2983 \pm 6 \mathrm{Ma}$ para ortognaisse G1 do terreno de alto grau do vale do Rio Jacurici, $3085 \pm 6 \mathrm{Ma}$ em gnaisse cinza migmatítico de Retirolândia e $2983 \pm 8$ Ma na parte félsica de gnaisse bandado da mina de cromita de Santa Luz. As idades modelo $\mathrm{T}_{\mathrm{DM}}$ e $\boldsymbol{\varepsilon}_{\mathrm{Nd(t)}}$ para essas rochas (Tabela 1) são, respectivamente, $3,21 \mathrm{Ga}(-2,14), 3,11 \mathrm{Ga}(1,46)$ e $3,04 \mathrm{Ga}(0,98)$, sugerindo pelo menos para o núcleo mais antigo de Retirolândia e Santa Luz (pelos $\boldsymbol{\varepsilon}_{\mathrm{Nd(t)}}$ positivos), origem em um provável contexto de arco magmático, possivelmente de margem continental, por se tratarem de rochas dominantemente granodioríticas cálcio-alcalinas a cálcio-alcalinas de alto $\mathrm{K}$.

\section{Complexo Caraíba}

Pela sua extensa área de exposição, esse complexo reveste-se de grande importância para o entendimento da evolução do orógeno. Silva et al. (1997) dataram ortognaisses granulíticos na região de São José de Jacuípe e encontraram idades de $2695 \pm 12$ Ma e $2634 \pm 19$ Ma nos núcleos de zircões e 2072 Ma em suas bordas metamórficas. As idades modelo $\mathrm{T}_{\mathrm{DM}}$, obtidas por nós para o afloramento datado em $2695 \mathrm{Ma}$ e seus equivalentes no terreno de alto grau do vale do Rio Curaçá, a norte, variam entre $2,83 \mathrm{Ga}$ e $2,71 \mathrm{Ga}, \operatorname{com} \boldsymbol{\varepsilon}_{\mathrm{Nd}(2695 \mathrm{Ma})}$ entre 0,49 e 1,71 (Tabela 1). A semelhança nas idades modelo dessas rochas e os valores positivos de $\varepsilon_{\mathrm{Nd}}$ são fortes evidências a favor da geração dos protólitos dos granulitos em ambiente de arco magmático, provavelmente de margem continental. Trabalhos anteriores incluíram no Complexo Caraíba os ortognaisses granulíticos do vale do Rio Jacurici, a leste do Sienito Itiúba (S na Figura 2). Entretanto, a idade U-Pb mais antiga dessas rochas (2983 Ma), comentada no item anterior, as exclui do referido complexo.

\section{Greenstone Belt do Rio Itapicuru}

Essa sequiência vulcano-sedimentar aflora no interior do Bloco Serrinha e tem sido interpretada como originada em uma bacia do tipo back-arc desenvolvida sobre crosta continental arqueana (Padilha \& Melo, 1991; Melo, 1995; Silva et al., 2001). A localização do arco magmático ainda não está bem estabelecida, mas Silva et al. (2001) sugerem que seja a oeste, com base na relação entre vulcânicas e sedimentos. Os dados geocronológicos para esta unidade indicam a se- 
Tabela 1. Dados representativos de isótopos de $\mathrm{N}$ d para rochas do Segmento Norte do 0 rógeno Itabuna-Salvador-Curaçá. Idades U-Pb: 1. Peucat et al. (2002). 2. O liveira et al. (2002). 3. Silva et al. (1997). 4. Mello et al. (2000). 5. Chauvet et al. (1997a). 6. Carvalho \& O liveira (2002). 7. Mello et al. (1999b). 8. Rios et al. (2000). 9. Este trabalho. Dados de Nd: amostras Peucat (Peucat etal., 2002); granitóides Teofilândia e Barrocas (Barrueto, 2002); Tonalito Itareru (Carvalho, 2001); Granodiorito Ambrósio (Lacerda, 2000); demais deste trabalho.

\begin{tabular}{|c|c|c|c|c|c|c|}
\hline Amostra & Litotipo & $\begin{array}{l}\text { Idade U-Pb } \\
\text { (Ma) }\end{array}$ & ${ }^{143} \mathrm{Nd} /{ }^{144} \mathrm{Nd}$ & $\begin{array}{l}\mathrm{T}_{\mathrm{DM}} \\
(\mathrm{Ma})\end{array}$ & $\varepsilon_{\mathrm{Nd}(0)}$ & $\varepsilon_{\mathrm{Nd}(\mathrm{t})}$ \\
\hline \multicolumn{7}{|l|}{ Bloco Gavião } \\
\hline PO-91 & Mairi migmat-gnaisse & $>3040^{1}$ & 0,510518 & 3464 & $-41,35$ & $-4,21$ \\
\hline PO-103 & Mairi ortognaisse & $>3040^{1}$ & 0,510608 & 3203 & $-39,60$ & $-0,71$ \\
\hline Peucat-526 & Mairi gnaisse & $>3040^{1}$ & 0,510357 & 3244 & $-44,50$ & $-1,50$ \\
\hline \multicolumn{7}{|c|}{ Greenstone Belt Mundo Novo } \\
\hline PO-119 & Mundo Novo metadacito & $3305^{1}$ & 0,510848 & 3587 & $-34,92$ & $-1,94$ \\
\hline Peucat-600 & Mundo Novo metadacito & $3305^{1}$ & 0,511044 & 3379 & $-31,09$ & 0,49 \\
\hline Peucat-680 & Mundo Novo metadacito & $3305^{1}$ & 0,511005 & 3433 & $-31,85$ & $-0,10$ \\
\hline \multicolumn{7}{|c|}{ Bloco Serrinha-Uauá } \\
\hline PO-45.2 & Jacurici G1 & $2983^{2}$ & 0,510540 & 2924 & $-40,92$ & 2,75 \\
\hline PO-46 & Jacurici G1 & $2983^{2}$ & 0,510246 & 3218 & $-46,67$ & $-2,14$ \\
\hline PO-9 & Retirolândia TTG & $3085^{2}$ & 0,510614 & 3116 & $-39,48$ & 1,16 \\
\hline P-Preta & P-Preta gn bandado félsico & $2983^{2}$ & 0,510985 & 3044 & $-32,24$ & 0,98 \\
\hline \multicolumn{7}{|c|}{ Complexo Caraíba } \\
\hline PO-102 & Granulito açude S.J.Jacuípe & $2695^{3}$ & 0,511086 & 2823 & $-30,27$ & 0,49 \\
\hline PPIN-3 & Curaçá G2 granulito & $2695^{3}$ & 0,510616 & 2754 & $-39,44$ & 1,18 \\
\hline AERO-C & Curaçá G2 granulito & $2695^{3}$ & 0,510826 & 2716 & $-35,35$ & 1,90 \\
\hline \multicolumn{7}{|c|}{ Greenstone Belt Rio Itapicuru } \\
\hline THB-1.6 & Tonalito Teofilândia & $2130^{4}$ & 0,511427 & 2190 & $-23,62$ & 2,38 \\
\hline THB-14.1 & Qz-pórfiro Teofilândia & $2130^{4}$ & 0,511440 & 2231 & $-23,37$ & 1,84 \\
\hline THB-4.2A & Tonalito Barrocas & $2127^{5}$ & 0,512109 & 2269 & $-10,31$ & 2,13 \\
\hline FB-135.60A & Tonalito Barrocas & $2127^{5}$ & 0,511678 & 2187 & $-18,73$ & 2,53 \\
\hline $\mathrm{JCl}-136 \mathrm{~b}$ & Tonalito Itareru & $2109^{6}$ & 0,511263 & 2329 & $-26,82$ & 0,00 \\
\hline SLM-16 & Tonalito Itareru & $2109^{6}$ & 0,511305 & 2345 & $-25,92$ & $-0,08$ \\
\hline $\mathrm{JCl}-79 \mathrm{a}$ & Tonalito Itareru & $2109^{6}$ & 0,511323 & 2401 & $-25,01$ & $-0,79$ \\
\hline $\mathrm{JCl} 150 \mathrm{~b}$ & Itareru xenólito anfibolito & $2109 ?$ & 0,511764 & 2272 & $-17,05$ & 1,49 \\
\hline CLAB-9B & Ambrósio dique granito & $2080^{7}$ & 0,510993 & 2644 & $-32,10$ & $-5,10$ \\
\hline CLAB-23 & Granodiorito Ambrósio & $2080^{7}$ & 0,511300 & 2807 & $-26,09$ & $-5,33$ \\
\hline CLAB-255 & Granodiorito Ambrósio & $2080^{7}$ & 0,511011 & 2586 & $-31,73$ & $-4,35$ \\
\hline PO-69 & Gnaisse domo Salgadália & - & 0,511086 & 3122 & $-30,27$ & - \\
\hline $\mathrm{JCl}-133$ & Granito Morro Lopes & $2072^{8}$ & 0,511255 & 3174 & $-28,98$ & $-8,53$ \\
\hline PO-18.2 & Granito Morro Lopes & $2072^{8}$ & 0,511201 & 2857 & $-28,03$ & $-6,37$ \\
\hline PO-70 & Metapelito & - & 0,511454 & 2349 & $-23,10$ & - \\
\hline GBRI-15 & Metapelito & - & 0,511591 & 2321 & $-20,42$ & - \\
\hline \multicolumn{7}{|c|}{ Seqüência Rio Capim } \\
\hline Craitu-2 & Dacito Rio Caratacá & $2148^{9}$ & 0,511245 & 2296 & $-27,17$ & 0,97 \\
\hline Craitu-3 & Dacito Rio Caratacá & $2148^{9}$ & 0,511258 & 2287 & $-26,92$ & 1,11 \\
\hline UA96-8.4 & Metapelito & - & 0,511380 & 2522 & $-24,54$ & - \\
\hline \multicolumn{7}{|c|}{ Complexo Saúde e Grupo Tanque Novo } \\
\hline PO-97 & Comp. Saúde Al-gnaisse & - & 0,511339 & 2608 & $-25,34$ & - \\
\hline AW 08 & Tanque Novo Al-gnaisse & - & 0,511434 & 2719 & $-29,16$ & - \\
\hline \multicolumn{7}{|c|}{ Granitóides no Complexo Caraíba } \\
\hline AERO-B & Curaçá G3-granito & - & 0,510719 & 2709 & $-37,44$ & - \\
\hline PO-110 & Capela qtz-monzonito & $2078^{9}$ & 0,510993 & 3157 & $-32,09$ & $-10,12$ \\
\hline ITIUBA 4 & Curaçá G3-Sienito Itiúba & $2084^{9}$ & 0,510992 & 2703 & $-32,11$ & $-5,77$ \\
\hline
\end{tabular}


guinte seqüência de eventos:

- 2209 × 60 Ma (isócrona Pb-Pb) - formação de vulcânicas máficas (Silva et al., 2001);

- $2170 \pm 60 \mathrm{Ma}$ (isócrona Pb-Pb) - formação de vulcânicas félsicas (Silva et al., 2001);

- 2155 土9 Ma (U-Pb SHRIMP e diluição isotópica) intrusão do granodiorito Trilhado (Mello et al., 2000) e cristalização do granito Quijingue (Rios et al., 2002);

- $2130 \pm 7 \mathrm{Ma}$ (U-Pb SHRIMP) e $2127 \pm 5 \mathrm{Ma}$ (evaporação de $\mathrm{Pb}$ ) - formação dos batólitos tonalito-granodioríticos de Teofilândia-Barrocas (Chauvet et al., 1997a; Mello et al., 2000);

- $2109 \pm 5 \mathrm{Ma}$ (U-Pb SHRIMP) - intrusão sintectônica do batólito Tonalito-Granodiorito Itareru no limite entre o Greenstone Belt do Rio Itapicuru e o embasamento (Carvalho \& Oliveira, 2002);

- $2080 \pm 2 \mathrm{Ma}$ (U-Pb SHRIMP) - formação de domos granodioríticos do tipo Ambrósio (Mello et al., 1999b);

- $2072 \pm 1 \mathrm{Ma}$ (U-Pb diluição isotópica) - intrusões graníticas tardi-tectônicas tipo Morro do Lopes (Rios et al., 2000).

Informações sobre isótopos de $\mathrm{Nd}$, apresentadas em Silva et al. (2001), indicaram idades modelo $\mathrm{T}_{\mathrm{DM}}$ de aproximadamente 2,2 Ga para metabasaltos e 2,12 Ga para andesitos, com $\boldsymbol{E}_{\mathrm{Nd}(\mathrm{t})}$ na maioria positivos ( +4 nos basaltos e +2 nos andesitos).

Para os corpos tonalito-granodioríticos de Barrocas e Teofilândia, Barrueto et al. (1998) e Barrueto (2002) também encontraram valores positivos de $\mathcal{E}_{\mathrm{Nd}}(+2,13 \mathrm{e}+2,58$ para Barrocas; +1,84 a +2,38 para Teofilândia), caracterizandoos, com base nessas informações, ausência de xenólitos do embasamento, e dados geoquímicos de elementos maiores e traços, como formados em um arco magmático intraoceânico.

O Tonalito-Granodiorito Itareru, por outro lado, contém xenólitos de anfibolitos, possivelmente de metabasaltos do greenstone (idade modelo de $2,27 \mathrm{Ga}$ ), e exibe idades modelo $\mathrm{T}_{\mathrm{DM}}$ no intervalo $2,32-2,40 \mathrm{Ga}$, com $\boldsymbol{\varepsilon}_{\mathrm{Nd}(2109)}$ entre $-0,72$ e 0 (Tabela 1), indicando parcial interação com crosta pré-existente, ou origem a partir de mistura na fonte.

Por outro lado, os corpos graníticos mais novos do Greenstone Belt do Rio Itapicuru, como os domos de Ambrósio (2080 Ma cf. Mello et al., 1999) e Salgadália, ou aqueles intrusivos no embasamento adjacente, como o Granito Morro do Lopes (2072 Ma cf. Rios et al., 2000), apresentam idades modelo $\mathrm{T}_{\mathrm{DM}}$ (Tabela 1$)$ mais antigas $(2,58 \mathrm{a}$ $3,21 \mathrm{Ga})$ e $\mathcal{E}_{\mathrm{Nd}(\mathrm{t})}$ bastante negativos $(-8,53 \mathrm{a}-4,35)$. Os xenólitos de gnaisses migmatíticos, por nós encontrados nessas rochas, e os dados de isótopos de $\mathrm{Nd}$ supracitados permitem interpretá-las como originadas após o fechamen- to da bacia vulcano-sedimentar, a partir da fusão parcial do embasamento, ou tendo forte contribuição deste.

\section{Seqüência Rio Capim}

Essa seqüência vulcano-sedimentar ocorre na borda oriental do Bloco Uauá e está em contato com rochas deste bloco através da zona de cisalhamento Galo do Ouro. Oliveira et al. (1998) apresentaram idade de 2153 Ma (isócrona $\mathrm{Pb}-\mathrm{Pb}$ ) para vulcânicas félsicas e $2138 \mathrm{Ma}$ a $2126 \mathrm{Ma}$ (U-Pb, diluição isotópica em zircões) em leucogabro e diorito. Dados U-Pb (SHRIMP) inéditos para as vulcânicas félsicas revelaram idade de $2148 \pm 16 \mathrm{Ma}$, confirmando a idade paleoproterozóica para esta unidade, e a semelhança temporal com o Greenstone Belt do Rio Itapicuru. Dados de isótopos de $\mathrm{Nd}$ para as vulcânicas dacíticas $\left(\mathrm{T}_{\mathrm{DM}}=2,28 \mathrm{e}\right.$ $2,29 \mathrm{Ga}$ e $\boldsymbol{E}_{\mathrm{Nd}(2148)}=0,97$ e 1,11$)$ e para sedimentos $\left(\mathrm{T}_{\mathrm{DM}}=\right.$ 2,52 Ga e $\left.\varepsilon_{\mathrm{Nd}(2148)}^{\mathrm{Nd}(148)}=-1,54\right)$ permitem concluir que pelo menos parte da Sequiência Rio Capim deve ter se formado em ambiente de arco continental.

O contraste de idades entre as rochas da Seqüência Rio Capim (2148 - 2126 Ma) e aquelas do Bloco Uauá (3160 $2933 \mathrm{Ma}$ ) e o contato brusco entre essas duas unidades indicam que a primeira foi acrescida à última e que a zona de cisalhamento Galo do Ouro tem um grande potencial de ser uma zona de sutura.

\section{G rupo Jacobina}

As informações geocronológicas em sedimentos dessa unidade são relevantes para o entendimento da evolução do orógeno.

Mougeot et al. (1996) estudaram zircões detríticos nos quartzitos e encontraram duas populações principais, uma mais antiga $(3,45$ - 3,35 Ga) e outra mais nova (aproximadamente 2080 Ma). Embora o Bloco Gavião aparentemente possa ter sido a principal fonte para os sedimentos, as direções das paleocorrentes apontam transporte dos mesmos para oeste, fato que levou os autores a sugerirem que a bacia foi preenchida, pelo menos em parte, por sedimentos erodidos de remanescentes do Bloco Gavião, a leste. Segundo Ledru et al. (1997), o Grupo Jacobina é uma bacia do tipo foreland associada ao Cinturão Salvador-Curaçá (aqui designado Segmento Norte do Orógeno Itabuna-Salvador-Curaçá).

\section{Complexo Saúde, Grupo Tanque Novo e Grupo Ipirá}

Essas unidades são constituídas dominantemente por rochas metassedimentares. Segundo Souza et al. (2000) e Kosin et al. (2001) os Grupos Tanque Novo e Ipirá possivelmente são crono-correlatos. Por outro lado, Leite (2002) 
considera que o Complexo Saúde e o Grupo Ipirá são correlacionáveis. Para essas unidades não há dados geocronológicos U-Pb disponíveis. Entretanto, as idades modelo Nd para gnaisses aluminosos do Grupo Tanque Novo (vale do Rio Curaçá) e Complexo Saúde indicam idades máximas, respectivamente, de cerca $2600 \mathrm{Ma}$ e $2700 \mathrm{Ma}$ para a sedimentação.

\section{Faixa Caldeirão}

Esta faixa ocorre na borda ocidental do Bloco Uauá, na região nordeste do Segmento Norte do orógeno, e é constituída por uma seqüência verticalizada de quartzitos, sillimanita-granada-cordierita-mica xistos/gnaisses e anfibolitos, intercalada com gnaisses e migmatitos do embasamento. Zircões detríticos de uma amostra de quartzito forneceram idades entre 2687 e 3209 Ma em seus núcleos, e cerca de 2076 Ma nas margens metamórficas (Mello et al., 1999b; Oliveira et al., 2002a). Conforme estes autores, a deposição dos protólitos dos quartzitos e dos xistos/gnaisses metapelíticos associados ocorreu entre $2687 \mathrm{Ma}$ (idade do zircão detrítico mais novo) e $2076 \mathrm{Ma}$, idade do metamorfismo em facies anfibolito. Curiosamente, a idade máxima para a sedimentação dos protólitos dos quartzitos assemelha-se às idades máximas para a deposição dos metassedimentos aluminosos do Complexo Saúde e do Grupo Tanque Novo, sugerindo que essas rochas possam ser crono-correlatas.

\section{Corpos plutônicos félsicos intrusivos no Complexo Caraíba}

Vários corpos félsicos alongados na direção N-S cortam os ortognaisses granulíticos do Complexo Caraíba. No vale do Rio Curaçá, eles são designados genericamente como intrusões G3 (e. g. Jardim de Sá et al., 1982), sendo o Sienito Itiúba o corpo-tipo. Mais para sul, eles foram denominados como granitóides sin- a pós-deformação transcorrente (e. $g$. Melo et al., 1991).

Dois desses corpos tiveram seus zircões datados pelo método U-Pb SHRIMP: o Sienito Itiúba, a norte, e um quarztomonzonito porfirítico de Capela do Alto Alegre, a sul. Quanto ao alojamento, o primeiro foi caracterizado como sintranstensão (Conceição et al., 1991) e o segundo como sindeformação transcorrente (granitóide tipo Conceição, segundo Melo et al., 1991).

Os resultados revelaram a idade de $2084 \pm 9$ Ma para o Sienito Itiúba e $2078 \pm 6$ Ma para o quartzo-monzonito de Capela do Alto Alegre, este com zircões mais antigos, provavelmente herdados da fonte crustal. O Sienito Itiúba apresenta idades modelo $\mathrm{Nd}_{\mathrm{DM}}$ no intervalo 2,70 - 2,81 Ga e $\varepsilon_{\mathrm{Nd(t)}}$ negativos $(-5,77 \mathrm{e}-8,51)$, e o quartzo-monzonito $\mathrm{T}_{\mathrm{DM}}=$ $3,15 \mathrm{Ga}$ e $\varepsilon_{\mathrm{Nd}(\mathrm{t})}$ também negativo (Tabela 1 ), sugerindo ori- gem a partir da fusão parcial de litosfera continental mais antiga, ou interação entre magma mantélico e a crosta continental.

\section{Metamorfismo de alto grau}

As melhores idades sobre o metamorfismo de alto grau no Segmento Norte do orógeno foram obtidas por Silva et al. (1997), Mello et al. (1999a) e Oliveira et al. (2002a). Os dados isotópicos apresentados por esses autores, entre $2082 \pm 10 \mathrm{Ma}$ e $2072 \pm 22 \mathrm{Ma}$, foram coletados em bordas de crescimento metamórfico nos zircões, as quais, como apresentado em Oliveira et al. (2002a), têm baixas razões Th/U (inferiores a 0,1 ), consideradas na literatura como típicas de zircões metamórficos (e.g. Rubatto \& Gebauer, 2000).

\section{DISCUSSÃO E CONCLUSÕES}

Os dados geocronológicos em zircões e isótopos de $\mathrm{Nd}$ em rocha-total demonstram uma longa história de formação de litosfera continental no Segmento Norte do Orógeno Itabuna-Salvador-Curaçá.

Acresções de crosta oceânica e/ou de arcos insulares ocorreram há aproximadamente 3300 Ma no Greenstone Belt de Mundo Novo (Mascarenhas \& Silva, 1994; Peucat et al., 2002, e este trabalho, Tabela 1), entre $2200 \mathrm{Ma}$ e 2127 Ma no Greenstone Belt do Rio Itapicuru (Silva, 1997; Chauvet et al., 1997a; Barrueto et al., 1998; Mello et al., 2000; Silva et al., 2001; Barrueto, 2002), e entre 2148 Ma e 2126 Ma na Seqüência Rio Capim (Oliveira et al., 1998; este trabalho, Tabela 1).

Os protólitos ígneos plutônicos do Complexo Caraíba podem ter-se formado em ambiente semelhante ao de arco continental tipo andino entre $2695 \mathrm{Ma}$ e $2634 \mathrm{Ma}$, com base nas idades apresentadas por Silva et al. (1997) e nos valores positivos de $\boldsymbol{\varepsilon}_{\mathrm{Nd}(t)}$ deste trabalho (Tabela 1), que indicam acresção de material juvenil à crosta continental (e.g. Condie, 1997). O mesmo raciocínio pode ser estendido aos ortognaisses do vale do Rio Jacurici e da região de Retirolândia e Santa Luz, formados entre 3085 Ma e 2983 Ma e com $\varepsilon_{\mathrm{Nd}(t)}$ positivos (este trabalho, Tabela 1).

A época da colisão continental que gerou a presente configuração do Segmento Norte do orógeno é mais incerta, mas uma idade mínima pode ser estimada a partir da evolução estrutural proposta para a porção sul do Greenstone Belt do Rio Itapicuru. Nesta região, Alves da Silva et al. (1993) e Chauvet et al. (1997a, b) propuseram uma evolução em dois estágios, com intrusões graníticas associadas. Segundo esses autores, a deformação mais antiga (D1) é dominada por empurrões e dobras com vergência para sudeste, e aconteceu durante a colisão continental que fechou a bacia vulcano-sedimentar. A idade obtida para o Granitóide 
Barrocas (2127 Ma, $c f$. Chauvet et al., 1997a) definiria a época da colisão. Em seguida, a tectônica compressiva mudou para direcional, com formação de várias zonas de cisalhamento norte-sul e forte foliação com a mesma orientação (D2). Durante este evento, formaram vários plútons graníticos, como o domo de Ambrósio, datado em $2080 \mathrm{Ma}$ por Mello et al. (1999b). Ao contrário do sugerido recentemente por Rios (2002), o domo de Ambrósio não pode ter idade mesoarqueana visto que:

1. os granodioritos e granitos que formam a maior parte do domo apresentam características ígneas de alojamento sintectônico ao evento D2 de Alves da Silva et al. (1993) e Chauvet et al. (1997b), tais como, estruturas de fluxo e lineações minerais paralelas às estruturas desenvolvidas em estado sólido nas encaixantes (lineações de estiramento mineral e foliação S2);

2. as rochas encaixantes do domo apresentam lineação de estiramento mineral desenvolvida durante o evento D1 de Alves da Silva et al. (1993) o que não é observado nos granodioritos do domo;

3. o domo está circundado por rochas metassedimentares do Greenstone Belt do Rio Itapicuru, para as quais foram obtidas idades modelo $\mathrm{Nd}$ de aproximadamente 2,3 Ga (Tabela 1). Como as rochas sedimentares clásticas finas representam uma média das fontes das quais derivaram, as suas idades modelo $\mathrm{Nd}$ podem ser consideradas como máximas para a deposição dos protólitos. Se a estrutura dômica arquea os metassedimentos, então ela tem que ter-se formado após aqueles;

4. os grãos de zircão datados por Mello et al. (1999b) são ígneos e não metamórficos, pois não apresentam razões $\mathrm{Th} / \mathrm{U}$ abaixo de 0,1 , diagnósticas de rochas metamórficas (Rubatto \& Gabauer, 2000).

Mapeamentos geológicos recentes de Carvalho (2001) e Barrueto (2002), respectivamente no Tonalito Itareru (2109 Ma) e nos Granitóides de Barrocas e Teofilândia (2127 Ma e $2130 \mathrm{Ma}$, respectivamente), sustentam uma nova interpretação para a época da colisão continental.

Segundo Barrueto (2002), os Granitóides Barrocas e Teofilândia constituem uma intrusão composta formada num ambiente de arco intra-oceânico. A leste, o Granitóide Teofilândia apresenta estruturas dominantemente magmáticas e quase nenhuma deformação dúctil, diferente do encontrado em suas porções central e ocidental. Aí, juntamente com o Granitóide Barrocas, ele apresenta bandas de cisalhamento mesoscópicas, antiformes e sinformes de grande amplitude, e forma uma grande estrutura amendoada, balizada por zonas de cisalhamento dúcteis dextrais. Por esses aspectos estruturais, Barrueto (2002) conclui que a deformação dúctil nos corpos de Barrocas e Teofilândia é posterior ao seu alojamento magmático e, portanto, não pode ter sido durante o evento D1, como proposto por Alves da Silva et al. (1993) e Chauvet et al. (1997a).

Por outro lado, Carvalho (2001) e Carvalho \& Oliveira (2002) descrevem o Tonalito Itareru como um corpo sintectônico alongado, de composição principalmente tonalítica a granodiorítica, alojado no limite entre gnaisses bandados do embasamento, a oeste, e anfibolitos e rochas metassedimentares do Greenstone Belt do Rio Itapicuru, a leste. Corpos semelhantes, em outras faixas orogênicas, definem o limite entre terrenos (e.g. Musumeci, 1999). O Tonalito Itareru contém xenólitos de anfibolito, provavelmente do Greenstone Belt do Rio Itapicuru, e está cortado por aplitos e pelo domo alongado de Lagoa do Boi e seus satélites, semelhantes estrutural, composicional e temporalmente ao domo de Ambrósio. Carvalho \& Oliveira (2002) concluem que a intrusão do Tonalito Itareru ocorreu durante a colisão continental que deu origem ao Orógeno ItabunaSalvador-Curaçá, correspondendo na região ao evento D1 supracitado.

Após a colisão continental, o Segmento Norte do orógeno foi afetado por uma tectônica direcional de grande magnitude, bem registrada em várias zonas de cisalhamento verticais e no bloco arqueano de Uauá.

Este bloco faz contato com a Seqüência Rio Capim, a leste, e com a Faixa Caldeirão, a oeste, através de zonas de cisalhamento de alto caimento, e está cortado por vários enxames de diques máficos. Imagens de satélite, relações de campo e dados geocronológicos confirmam que o Bloco Uauá é um "terreno extrusado" no Segmento Norte do Orógeno Itabuna-Salvador-Curaçá (Oliveira et al., 2001, 2002c). De fato, o arrasto sinistral dos diques máficos na porção ocidental do Bloco Uauá, nitidamente observado em imagem de satélite, e indicadores cinemáticos dextrais (relação S-C e dobras assimétricas sin-milonitização) na zona de cisalhamento Galo do Ouro, no seu limite oriental, indicam que o Bloco Uauá deslocou vários quilômetros de sul para norte.

Uma idade mínima de $2039 \pm 2$ Ma foi sugerida por Oliveira et al. (2001 e 2002c) para a tectônica de extrusão, ou de escape, a partir da datação U-Pb em multigrãos de titanita sin-metamórfica provenientes de dique máfico boudinado na borda ocidental do Bloco Uauá (Oliveira et al., 2000). Entretanto, o escape de blocos deve ter iniciado bem antes, como inferido pela intrusão de vários corpos graníticos alongados no Segmento Norte do orógeno (Sienito Itiúba, 2084 Ma; domo de Ambrósio, 2080 Ma; quartzo-monzonito de Capela do Alto Alegre, $2078 \mathrm{Ma}$ ) e pela idade U-Pb SHRIMP (2076 Ma) em crescimentos metamórficos em zircões detríticos dos quartzitos da Faixa Caldeirão.

$\mathrm{O}$ agente que causou a mudança de um regime inicial de convergência de massas continentais para outro de deslo- 
camento lateral ao longo do orógeno ainda não está bem compreendido. A colisão pode ter sido oblíqua, caso em que a passagem de um regime para o outro é facilitada, ou ter sido semelhante à evolução dos Himalaias (e. $g$. Tapponnier et al., 1986). Neste caso, o Bloco Serrinha, ou algum remanescente similar, a sudeste-leste do mesmo, pode ter agido como o cinzel que provocou a endentação e concomitante extrusão de blocos, como o de Uauá. Qualquer que seja o modelo, ele deve necessariamente considerar as idades aqui apresentadas e os registros de vergência de estruturas não só para sudeste, mas também para leste no Bloco Serrinha-Uauá (e. g. Lacerda, 2000; Carvalho, 2001; Tezini \& Oliveira, 2002).

Por fim, o Segmento Norte do Orógeno Itabuna-Salvador-Curaçá juntamente com o Segmento Sul compõem um orógeno colisional ( $c f$. Windley, 1995), constituído por diversos terrenos, com idades e evoluções diferentes. A correlação cronológica e estrutural entre os dois segmentos e a compreensão do papel desempenhado pelo ramo que segue para nordeste, a partir de Salvador, são desafios inadiáveis para o entendimento geotectônico desta importante faixa orogênica do território brasileiro.

\section{AGRADECIMENTOS}

Carla Lacerda, Edson Mello, Hector Barrueto, Luiz Cesar Corrêa Gomes, Marcelus Glaucus Araújo, Marco Paixão, Maria Irian Duarte e Zorano Sérgio de Souza pelas discussões sobre vários aspectos da geologia da região nordeste do estado da Bahia. Aos professores Randy Van Schmus (Kansas University) e Marcio Pimentel (Universidade de Brasília) pela oportunidade de utilização dos laboratórios isotópicos. Ao CNPq e à FAPESP pelos recursos concedidos na forma de bolsas de pesquisa no Brasil e exterior, assim como para o desenvolvimento dos projetos de pesquisa. Os comentários de dois relatores anônimos enriqueceram significativamente o texto.

\section{REFERÊNCIAS BIBLIOGRÁFICAS}

ALVES DA SILVA, F. C.; CHAUVET, A.; FAURE, M. Early Proterozoic orogeny (Transamazonian) and syntectonic granite emplacement in the Rio Itapicuru greenstone belt, Bahia, Brazil. Comptes Rendus de l'Academie des Sciences. Paris II, v. 316, p. 1139-1146, 1993.

BARBOSA, J. S. F. Síntese do conhecimento sobre a evolução geotectônica das rochas metamórficas arqueanas e paleoproterozóicas do embasamento do Cráton do São Francisco na Bahia. Revista Brasileira de Geociências, v. 27, p. 241-256, 1997.

BARBOSA, J. S. F. The granulites of the Jequié Complex and Atlantic Mobile Belt, southern Bahia, Brazil - an expression of Archean-Proterozoic plate convergence. In: VIELZEUF, D.; VIDAL, P. (eds.) Granulites and crustal evolution. Boston: Kluwer, Academic, 1990. p. 195-221.

BARBOSA, J. S. F.; OLIVEIRA, E. P.; CORRÊAA GOMES, L. C.; MARINHO, M. M.; MELO, R. C. I. Geologia e Guia de Excursão. In: WORKSHOP SOBRE O ORÓGENO ITABUNA-SALVADOR-CURAÇÁ, 2001. Salvador.

BARBOSA, J. S. F.; SABATÉ, P. Geological features and the Paleoproterozoic collision of four Archean crustal segments of the São Francisco Craton, Bahia, Brazil: a syntheis. Anais da Academia Brasileira de Ciências, v. 74, p. 343-359, 2002.

BARRUETO, H. R. Petrogênese das intrusões compostas de Teofilândia e Barrocas, Greenstone Belt do Rio Itapicuru, Bahia, Brasil. 2002. 188 f. Tese (Doutorado) Instituto de Geociências, UNICAMP.

BARRUETO, H. R.; OLIVEIRA, E. P.; DALL'AGNOL, R. Trace element and Nd isotope evidence for juvenile, arcrelated granitoids in the southern portion of the Paleoproterozoic Rio Itapicuru Greenstone Belt (RIGB), Bahia, Brazil. In: CONGRESSO BRASILEIRO DE GEOLOGIA, 40., 1998. Belo Horizonte. Anais. Belo Horizonte: SBG, 1998. p. 520.

CARVALHO, M. J. Geologia e geoquímica do TonalitoDiorito Itareru, borda ocidental do Greenstone Belt do Rio Itapicuru, Bahia. 2001. 71 f. Dissertação (Mestrado) - Instituto de Geociências, UNICAMP, Campinas.

CARVALHO, M. J.; OLIVEIRA, E. P. The Itareru Tonalite: an elongated, sin-collisional body in the Serrinha Block of the Itabuna-Salvador-Curaçá Orogen. Simpósio Faixas Móveis Proterozóicas. In: CONGRESSO BRASILEIRO DE GEOLOGIA, 41., 2002. João Pessoa. Anais. João Pessoa: SBG, 2002.p.

CHAUVET, A.; GUERROT , C.; ALVES DA SILVA F. C.; FAURE, M. Géochronologie ${ }^{207} \mathrm{~Pb} /{ }^{206} \mathrm{~Pb}$ et ${ }^{40} \mathrm{Ar} /{ }^{39} \mathrm{Ar}$ des granites paléoprotérozoiques de la ceinture de roches vertes du Rio Iapicuru (Bahia, Brésil). Comptes Rendus de l'Academie des Sciences. Paris II, v. 324, p. 293-300, 1997.

CHAUVET, A.; SILVA, F. C. A.; FAURE, M.; GUERROT, C. Structural evolution of the Paleoproterozoic Rio Itapicuru granite-greenstone belt (Bahia, Brazil): the role of synkinematic plutons in the regional tectonics. Precambrian Research, v. 84, p. 139-162, 1997.

CONCEIÇÃO, H.; SABATÉ, P.; BONIN, B. The Itiúba alkaline syenite massif, Bahia State (Brazil): mineralogical, geochemical and petrological constraints - relation to the genesis of rapakivi magmatism. Precambrian Research, v. 51, p. 283-314, 1991.

CONDIE, K. Plate tectonics and crustal evolution. 4.ed. 
Butterworth Heinemann. 282 p. 1997

CORDANI, U.G.; SATO, K.; NUTMAN, A. Single zircon SHRIMP determination from Archean tonalitic rocks near Uauá, Bahia, Brazil. In: SOUTH AMERICAN SYMPOSIUM ON ISOTOPE GEOLOGY, 2., 1999. Córdoba, Argentina. Proceedings. Córdoba: Instituto de Geologia y Recursos Minerales, 1999. p. 27-30.

COSTA, L. A. M.; MASCARENHAS, J. F. The high-grade metamorphic terrains in the interval Mutuipe-Jequié: Archean and Lower Proterozoic of east-central Bahia. In: INTERNATIONAL SYMPOSIUM ON ARCHEAN ANDEARLYPROTEROZOICGEOLOGICEVOLUTION AND METALLOGENESIS, 1982. Salvador, Brazil. Abstracts excursions. Salvador: Secretaria, 1982. p. 19-37.

FIGUEIREDO, M. C. H. Geochemical evolution of eastern Bahia, Brazil: a probable Early Proterozoic subductionrelated magmatic arc. Journal of South American Earth Sciences, v. 2, n. 2, p. 131-145, 1989.

FIGUEIREDO, M. C. H., BARBOSA, J. S. F. Terrenos metamórficos de alto grau do cráton do São Francisco. In: DOMINGUEZ, J.M.L. \& MISI, A. (Eds.) O Cráton do São Francisco. Salvador: SBG/SGM/CNPq. p. 63-83, 1993.

JARDIM DE SÁ, E. F.; ARCHANJO, C. J.; LEGRAND, J. M. Structural and metamorphic history of part of the highgrade terrain in the Curaçá Valley, Bahia, Brazil. Revista Brasileira de Geociências, v. 12, p. 251-262, 1982.

KOSIN, M.; GUIMARÃES, J. T.; ABRAM, M. B. (Orgs.) Folha Aracaju-SW: SC.24-Y. Salvador : CPRM, 1999. (Programa Levantamentos Geológicos Básicos do Brasil).

KOSIN, M.; MELO, R.C.; OLIVEIRA, E.P. (2001) Geologia do Bloco Serrinha e do segmento norte do Orógeno Itabuna-Salvador-Curaçá. In: BARBOSA, J.S.F, OLIVEIRA, E. P., CORRÊA GOMES, L. C., MARINHO, M. M., MELO, R. C. (eds) In: WORKSHOP SOBREO ORÓGENO ITABUNA-SALVADOR-CURAÇÁ, 2001. Salvador. Cap. 3, $19 \mathrm{p}$.

KOSIN, M.; MELO, R. C.; SOUZA, J. D.; OLIVEIRA, E. P.; CARVALHO, M. J.; LEITE, C. M. M. Geologia do segmento norte do Orógeno Itabuna-Salvador-Curaçá e guia de excursão. Revista Brasileira de Geociências, v. 33 (no prelo).

LACERDA, C. M. M. Evolução Estrutural e Petrogenética do Domo Granodiorítico de Ambrósio, Greenstone Belt do Rio Itapicuru, Bahia. 2000. 174 f. Tese (Doutorado) Instituto de Geociências, UNICAMP.

LEDRU, P.; COCHERIE, A.; BARBOSA, J.; JOHAN, V.; ONSTOTT, T. Ages du métamorphisme granulitique dans le craton du São Francisco (Brésil). Implications sur la nature de l'orogène transamazonien. Comptes Rendus de l'Academie des Sciences. Paris II, v. 318, p. 251-257,
1994.

LEDRU, P.; MILÉSI, J. P.; JOHAN, V.; SABATÉ, P.; MALUSKI, H. Foreland basins and gold-bearing conglomerates: a new model for the Jacobina Basin (São Francisco province, Brazil). Precambrian Research, v. 86, p. 155-176, 1997.

LEITE, C.M.M. A evolução geodinâmica da orogênese paleoproterozóica nas regiões de Capim Grosso Jacobian e Pintadas - Mundo Novo (Bahia, Brasil): Metamorfismo, anatexia crustal e tectônica. 2002. $412 \mathrm{f}$. Tese (Doutorado) - Instituto de Geociências, Universidade Federal da Bahia.

MARTIN, H.; SABATE, P.; PEUCAT, J. J.; CUNHA, J. Un segment de croûte continentale d'âge archéen ancient (3.4 milliards d'années): le massif de Sete Voltas (Bahia, Brésil). Comptes Rendus de l'Academie des Sciences. Paris II, v. 313, p. 531-538, 1991.

MARTIN, H.; PEUCAT, J. J.; SABATE, P.; CUNHA, J. Crustal evolution of the early Archean of South America: example of the Sete Voltas Massif, Bahia State, Brazil. Precambrian Research, v. 82, p. 35-62, 1997.

MASCARENHAS, J. F.; SILVA, E. F. A. Greenstone Belt de Mundo Novo: caracterização e implicações metalogenéticas e geotectônicas no Cráton do São Francisco. Série Arquivos Abertos, n.5, p.1-31, 1994.

MASCARENHAS, J.H. Estruturas do tipo greenstone belt no leste da Bahia. In: Geologia e recursos minerais do Estado da Bahia. Salvador: SME/COM, 1979. v. 2, p. 25-53.

MELLO, E. F.; OLIVEIRA, E. P.; MCNAUGHTON, N. SHRIMP U-Pb geochronology of Early Precambrian quartzite and its basement (Caldeirão Belt), NE Sao Francisco Craton, Bahia-Brazil. In: SOUTHAMERICAN SYMPOSIUM ON ISOTOPE GEOLOGY, 2., 1999. Córdoba. Actas. Córdoba: SEGEMAR, 1999. p. 78-81.

MELLO, E. F.; LACERDA, C. M. M.; OLIVEIRA, E. P.; MCNAUGHTON, N. SHRIMP U-Pb geochronology on xenotime and zircon from the Ambrosio dome, Rio Itapicuru Greenstone Belt, Brazil: a major syntectonic granodiorite intrusion. In: SOUTH AMERICAN SYMPOSIUM ON ISOTOPE GEOLOGY, 2., 1999. Córdoba. Actas. Córdoba: SEGEMAR, 1999. p.331-334.

MELLO, E. F.; XAVIER, R. P.; MCNAUGHTON, N.; FLETCHER, I.; LACERDA, C. M. M.; OLIVEIRA, E. P. Age constraints of felsic intrusions, metamorphism, deformation and gold mineralization in the Paleoproterozoic Rio Itapicuru Greenstone Belt, NE Bahia State, Brazil. In: INTERNATIONAL GEOLOGICAL CONGRESS, 31., 2000. Rio de Janeiro. General Symposium Stable and radiogenic isotopes in Metallogenesis. Rio de Janeiro, 2000. 1 CD-ROM.

MELO, R. C.; SILVA, L. C.; FERNANDES, P. C. Estratigrafia. 
In: MELO, R. C. (Org.) Pintadas - Folha SC.24-Y-D-V. Brasilia: CPRM, 1991. p.23-47. (Programa de Levantamentos Geológicos Básicos do Brasil).

MELO, R. C. (1995) Tectônica. In: MELO, R.C., LOUREIRO, H.S.C.; PEREIRA, L.H.M. (Orgs.) Serrinha - Folha SC.24Y-D. Brasília : CPRM, 1995. p.41-50. (Programa de Levantamentos Geológicos Básicos do Brasil).

MOUGEOT, R.; RESPAUT, J. P.; LEDRU, P.; MILESI, J. P.; JOHAN, V. U-Pb geocronological constraints for the evolution of the Paleoproterozoic Jacobina auriferous basin (São Francisco Province, Bahia, Brazil). In: CONGRESSO BRASILEIRO DE GEOLOGIA, 39., 1996. Salvador. Proceedings. Salvador: SBG, 1996. v. 6, p. 582-584.

MUSUMECI, G. Magmatic belts in accretionary magins, a key for tectonic evolution: the Tonalite Belt of North Vuctoria Land (East Antarctica). Journal of the Geological Society. London, v. 156, p. 177-189, 1999.

NUTMAN, A. P.; CORDANI, U. G.; SHRIMP U-Pb zircon geochronology of Archean granitoids from the Contendas-Mirante area of the São Francisco Craton, Bahia, Brazil. Precambrian Research, v. 63, p. 179-188, 1993.

OLIVEIRA, E. P.; TARNEY, J. Genesis of the copper-rich Caraiba norite-hypersthenite complex, Brazil. Mineralium Deposita, v. 30, p. 351-373, 1995.

OLIVEIRA, E. P.; LAFON, J. M.; SOUZA, Z. S. A Paleoproterozoic age for the Rio Capim volcano-plutonic sequence, Bahia, Brazil: whole-rock $\mathrm{Pb}-\mathrm{Pb}, \mathrm{Pb}$-evaporation and U-Pb constraints. In: CONGRESSO BRASILEIRO DE GEOLOGIA, 40., 1998. Belo Horizonte. Anais. Belo Horizonte: SBG, 1998. p. 14.

OLIVEIRA, E. P.; LAFON, J-M.; SOUZA, Z. S. ArchaeanProterozoic transition in the Uauá Block, NE São Francisco Craton, Brazil: $\mathrm{U}-\mathrm{Pb}, \mathrm{Pb}-\mathrm{Pb}$ and $\mathrm{Nd}$ isotope constraints. In: INTERNATIONAL SYMPOSIUM ON TECTONICS OF THE BRAZILIAN GEOLOGICAL SOCIETY, 1999. Lençóis. Abstract Volume. Lençóis, 1999. p. 38-40.

OLIVEIRA, E. P.; SOUZA,Z. S.; CORRÊA-GOMES, L.C. U$\mathrm{Pb}$ dating of deformed mafic dyke and host gneiss: implications for understanding reworking processes on the western margin of the Archaean Uauá Block, NE São Francisco Craton, Brazil. Revista Brasileira de Geociências, v. 30, p. 149-152, 2000.

OLIVEIRA, E. P.; CARVALHO, M. J.; DUARTE, M. I. D. Extrusion of the Archaean Uauá Block in the northern segment of the Itabuna-Salvador-Curaçá orogen, Bahia, and implications for diamond prospecting. In: SYMPOSIUM ON DIAMOND GEOLOGY, 3., 2001. Brazilia. p. 35.

OLIVEIRA, E. P.; MELLO, E. F.; MCNAUGHTON, N. Re- connaissance U-Pb geochronology of early Precambrian quartzites from the Caldeirão belt and their basement, NE São Francisco Craton, Bahia, Brazil: Implications for the early evolution of the Palaeoproterozoic SalvadorCuraçá Orogen. Journal of South American Earth Sciences, v.15, n. 3, p. 284-298, 2002a.

OLIVEIRA, E. P.; MELLO, E. F.; MCNAUGHTON, N.; CHOUDHURI, A. SHRIMPU-Pb age of the basement to the Rio Itapicuru Greenstone Belt, NE São Francisco Craton. In: CONGRESSO BRASILEIRO GEOLOGIA, 41., 2002. João Pessoa. Anais. João Pessoa: SBG-Núcleo Nordeste, 2002b. p. 522.

OLIVEIRA E. P.; CARVALHO M. J.; DUARTE M. I. M. Extrusion of the Archaean Uauá Block during Palaeoproterozoic continent-continent collision northern segment of the Itabuna-Salvador-Curaçá orogen, Bahia. In: CONGRESSO BRASILEIRO GEOLOGIA, 41., 2002c. Anais. João Pessoa: SBG-Núcleo Nordeste, 2002. p. 324.

OLIVEIRA E. P.; CHOUDHURI A.; MELLO E. F.; MCNAUGHTON, N. SHRIMP U-Pb geochronology of the basement to the Rio Itapicuru granite-greenstone belt, Bahia, Brazil. Gondwana Research (a submeter).

PADILHA, A.V.; MELO, R. C.; PEREIRA, L. H. M.; SAMPAIO, A. R.; LOUREIRO, H. S. C.; TEIXEIRA, L. R.; MOTTA, A. C. Orógeno Curaçá-Ipirá/ Uma contribuição à geologia da região centro-nordeste do Estado da Bahia. In: CONGRESSO BRASILEIRO DE GEOLOGIA, 36., Natal. Boletim de Resumos. Natal: SBG, 1990. p. 346.

PADILHA, A.V.; MELO, R. C. Estruturas e tectônica. In: MELO R. C. (org.) Pintadas - Folha SC.24-Y-D-V, Estado da Bahia. Brasília: CPRM (Programa Levantamentos Geológicos Básicos do Brasil).

PAIXÃO, M. A. P.; OLIVEIRA, E. P. The Lagoa da Vaca complex: an Archaean layered anorthosite body on the western edge of the Uauá Block, Bahia, Brazil. Revista Brasileira de Geociências, v. 28, p. 201-208, 1998.

PEUCAT, J. J.; MASCARENHAS, J. F.; BARBOSA, J. S.; SOUZA, F. S.; MARINHO, M. M.; FANNING, C. M.; LEITE, C. M. M. 3.3 Ga SHRIMP U_Pb zircon age of a felsic metavolcanic rock from the Mundo Novo greenstone belt in the São Francisco craton, Bahia (NE Brazil). Journal South American Earth Sciences, v. 15, p. 363-373, 2002.

RIOS, D. C. Granitogênese no Núcleo Serrinha, Bahia, Brasil: geocronologia e litogeoquímica. 2002. 239 f.. Tese (Doutorado) - Instituto de Geociências, Universidade Federal da Bahia.

RIOS, D. C.; CONCEIÇÃO, H.; DAVIS, D. W.; MARINHO, M. M.; ROSA, M. L. S. Os cristais de zircão mais velhos da América do Sul. In: CONGRESSO BRASILEIRO DE 
GEOLOGIA, 41., 2002. João Pessoa. Anais. João Pessoa: SBG, 2002. p. 526.

RIOS, D. C.; DAVIS, D. W.; CONCEIÇÃO, H.; MACAMBIRA, M. J. B.; PEIXOTO, A. A.; CRUZ FILHO, B. E.; OLIVEIRA, L. L. Ages of granites of the Serrinha Nucleus, Bahia (Brazil): an overview. Revista Brasileira de Geociências, v. 30, p. 74-77, 2000.

RUBATTO, D.; GEBAUER, D. Use of cathodoluminescence for $\mathrm{U}-\mathrm{Pb}$ zircon dating by ion microprobe: some examples from the Western Alps. In: PAGEL, M., BARBIN, V.; BLANC, P., OHNENSTETTER, D. (Eds) Cathodoluminescence in Geosciences. Springer Verlag, 2000. p. 373-400.

SABATÉ, P.; PEUCAT, J. J.; MELO, R. C.; PEREIRA, L. H. M. Datação por $\mathrm{Pb}$-evaporação de monozircão em ortognaisse do Complexo Caraíba: expressão do acrescimento crustal transamazônico do Cinturão Salvador-Curaçá (Cráton do São Francisco, Bahia, Brasil). In: CONGRESSOBRASILEIRODEGEOLOGIA, 38., 1994. Camboriú. Boletim de Resumos Expandidos. Camboriú: SBG, 1994. v. 1, p. 219-220.

SANTOS, R.A.; SOUZA, J.D. Projeto mapas metalogenéticos e de previsão de recursos minerais: Serrinha, folha SC.24-Y-D. Brasília : DNPM/CPRM, 1985. 12 p. Escala 1:250.000.

SILVA, L.C.; MCNAUGHTON, N.J.; MELO, R.C.; FLETCHER, I.R. U-Pb SHRIMP ages in the ItabunaCaraíba TTG high-grade complex: the first window beyond the Paleoproterozoic overprinting of the eastern Jequié craton, NE Brazil. In: International symposium on granites and associated mineralizations, 2., 1997. Salvador. Proceedings. Salvador: Sociedade Brasileira de Geologia, 1997. p. 282-283.

SILVA, M. G. Geoquímica, geocronologia e isótopos (Sm-Nd e $\mathrm{Pb}-\mathrm{Pb}$ ) da Sequiência Vulcano-Sedimentar do Rio Itapicuru (Bahia, Brasil) revelando uma parte da história da evolução crustal, proterozóica inferior, do Cráton do São Francisco. In: SEMANA DE GEOQUÍMICA, 10; CONGRESSO DE GEOQUÍMICA DOS PAISES DE LÍNGUA PORTUGUESA, 4., 1997. Braga. Actas. Braga: Universidade do Minho, 1997. p. 409-412.

SILVA, M. G.; COELHO, C.E. S.; TEIXEIRA, J. B. G.; ALVES DA SILVA, F. C.; SILVA, R. A.; SOUZA, J. A. B. The Rio Itapicuru greenstone belt, Bahia, Brazil: geologic evolution and review of gold mineralization. Mineralium Deposita, v. 36, p. 345-357, 2001.

SOUZA, J. D.; ABRAM, M. B.; SANTOS, R. A.; MELO, R.C. (2000) The basement of the northeastern São Francisco Craton. Field trip. Salavador: CPRM/Geological Survey of Brazil, 2000.

TAPPONNIER, P.; PELTZER, G.; ARMIJO, R. On the mechanics of the collision between India and Asia. In: COW-
ARD, M. P.; RIES, A. C. (Eds.) Collision tectonics. Oxford: Geological Society, 1986. p.115-157. (Geological Society Special Publication, 19).

TEIXEIRA, W.; FIGUEIREDO, M. C. H. An outline of Early Proterozoic crustal evolution in the São Francisco Craton, Brazil: a review. Precambrian Research, v. 53, p. 1-22, 1991.

TEIXEIRA, W.; SABATÉ, P.; BARBOSA, J.; NOCE, C. M.; CARNEIRO, M. A. Archean and Paleoproterozoic Tectonic Evolution of the São Francisco Craton. In: CORDANI, U. G.; MILANI, E. J.; THOMAZ FILHO; CAMPOS, D.A. (Eds) In: Tectonic evolution of South America. Rio de Janeiro, 2000. p. 101-137.

TEZINI, F. C.; OLIVEIRAE. P. O granito elíptico do Riacho do Traga: marcador de retrabalhamento do Bloco Arqueano de Uauá (Bahia) durante colisão continental paleoproterozóica. In: CONGRESSO BRASILEIRO GEOLOGIA, 41., 2002. João Pessoa. Anais. João Pessoa: SBG, 2002.p. 344.

WINDLEY, B. F. The evolving continents. 3 ed. New York: John Wiley \& Sons, 1995. 526 p. 